\title{
Cause-specific mortality in classic Kaposi's sarcoma: a population-based study in Italy (1995-2002)
}

\author{
V Ascoli*, , G Minelli ${ }^{2}$, M Kanieff ${ }^{2}$, R Crialesi ${ }^{3}$, L Frova $^{3}$ and S Conti ${ }^{2}$ \\ 'Dipartimento di Medicina Sperimentale, Università La Sapienza, Viale Regina Elena 324, 00161 Rome, Italy; ${ }^{2}$ Ufficio di Statistica, Istituto Superiore di \\ Sanità, Viale Regina Elena 299, 00161 Rome, Italy; ${ }^{3}$ Servizio Sanità e Assistenza, ISTAT, Viale Liegi 13, 00198 Rome, Italy
}

BACKGROUND: Little information is available on the causes of death among persons with classic Kaposi's sarcoma (CKS).

METHODS: We conducted a population-based study in Italy to identify deceased persons with CKS and the underlying causes of death among them, by reviewing multiple-causes-of-death records. Standardised mortality ratios (SMRs) and $95 \%$ confidence intervals were calculated to compare the distribution of causes to that among the same-age general population of deceased persons. The geographical distribution was also evaluated.

RESULTS: Of the 946 deaths among persons with CKS, 65.9\% were attributable to non-neoplastic conditions and $21.9 \%$ to malignancies. For 12.2\%, no lethal pathology was identified and CKS was considered as the underlying cause. In $90 \%$ of these cases, there was visceral/nodal involvement, therapy-related complications, or neoplastic cachexia. Among persons with CKS who died of other causes, an excess for lymphoid malignancies emerged (SMR = 4.40) (chronic lymphocytic leukaemia (I I.03), non-Hodgkin's lymphoma (4.22), Hodgkin's lymphoma ( I I.80), and multiple myeloma (2.3)), balanced by a deficit for all solid cancers (0.56), with a marked deficit for lung cancer (0.4I). We found an excess for respiratory diseases (chronic obstructive pulmonary disease (I.86)) and genitourinary diseases (chronic renal failure (6.47)). There was marked geographical heterogeneity in the distribution of deaths. CONCLUSIONS: Though referring specifically to Italy, the results are informative for other countries and populations and all cases of CKS in general.

British Journal of Cancer (2009) I 01, I085-1090. doi:I0.1038/sj.bjc.6605265 www.bjcancer.com

Published online 25 August 2009

(C) 2009 Cancer Research UK

Keywords: CKS; multiple-causes-of-death; mortality; death certificate; epidemiology

Classic (or 'Mediterranean') Kaposi's sarcoma (CKS) occurs in elderly persons of mainly Mediterranean origin and is a rare outcome of infection with the human herpesvirus 8 (HHV8). Several studies have found an association (either positive or negative) between CKS and an additional primary cancer, both when CKS was the first primary neoplasm (Franceschi et al, 1996; Hjalgrim et al, 1997; Iscovich et al, 1999a) and when it was the second primary neoplasm (Iscovich et al, 1999b; Hisada et al, 2001), or regardless of the temporal order of diagnosis (Cannon et al, 2000). A few studies have also reported an association (positive or negative) with a variety of non-neoplastic diseases (Goedert et al, 2002; Guttman-Yassky et al, 2006; Anderson et al, 2008).

Classic Kaposi's sarcoma is rarely considered to be an actual cause of death (Brambilla et al, 1994; Franceschi et al, 1996; Hiatt et al, 2008). However, little information is available on the causes of death among persons with CKS. No population-based studies have been conducted, and the available information derives from the sparse data retrieved from case series (Brambilla et al, 1994; Lospalluti et al, 1995; Franceschi et al, 1996; Hiatt et al, 2008). Furthermore, whereas the 10th revision of the International

*Correspondence: Dr V Ascoli, Dipartimento di Medicina Sperimentale, Anatomia Patologica, Università La Sapienza, Viale Regina Elena 324, 00 I6I Rome, Italy; E-mail: valeria.ascoli@uniromal.it

Received 27 May 2009; revised 22 July 2009; accepted 23 July 2009; published online 25 August 2009
Classification of Diseases (ICD-10) has a specific code for Kaposi's sarcoma (KS), the ICD-9, which in many countries is still used, does not.

The objectives of this study were to investigate cause-specific mortality among deceased persons with CKS and to determine whether the distribution of the underlying causes differs compared with the general population of deceased persons. To this end, we conducted a population-based study in Italy, which is one of the countries with the highest incidence rates of CKS in the Mediterranean basin and where HHV8 infection is endemic. Specifically, we reviewed multiple-causes-of-death records, which have never been used to study mortality among persons with CKS; we also evaluated the distribution by geographical area.

\section{MATERIALS AND METHODS}

\section{Data sources}

We used two data sources: the multiple-causes-of-death records and the National Mortality Database, both managed by Italy's National Census Bureau (ISTAT). The multiple-causes-of-death records are individual anonymous electronic records, which contain, in addition to the underlying cause (that is, the disease or injury that initiated the chain of events leading directly to death), all causes of death exactly as typewritten out in full by the medical examiner on the death certificate, in particular: (i) 'other 
causes resulting in the underlying cause', (ii) 'other significant conditions' (that is, those contributing to death yet not part of the chain of events leading directly to death), and (iii) the 'immediate/ final cause of death' (that is, the final disease, injury or complication directly causing death) (Israel et al, 1986; Wall et al, 2005). The only geographical information collected in this database is the province of death. The National Mortality Database contains only the underlying cause of death, which until 2003 was coded using ICD-9 (KS codified as 173.9, 'other malignant neoplasm of skin site unspecified'). It also contains the province of birth.

The analysis was conducted on data referring to the period from 1995 (that is, the year in which the multiple-causes-of-death records became available) to 2002 (that is, the year of the most recent available data). We excluded deaths in the provinces of Trento and Bolzano (both of which have small populations) because these provinces do not record the multiple causes written out in full.

\section{Identification of deceased persons with CKS}

Using the multiple-causes-of-death records, we identified all persons for whom the term 'Kaposi' was written as any of the above-mentioned causes ( $n=1967$, out of a total of 4452169 records). To exclude AIDS-related KS deaths, we carried out the following: (i) we eliminated the records with mention of HIV or AIDS anyplace on the death certificate; (ii) we manually reviewed the remaining individual records and excluded those with mention of AIDS-indicator opportunistic infections (WHO, 1994) (steps (i) and (ii) resulted in the elimination of 902 records); and (iii) we excluded all records for persons $<65$ years of age $(n=89)$, limiting the analysis to older persons, who have an extremely low prevalence of HIV/AIDS (Dal Maso et al, 2005); in our records, only $4.5 \%$ of the decedents with KS and mention of HIV/AIDS were aged $\geqslant 65$ years. To exclude transplant-associated KS, we eliminated the records that mentioned transplants $(n=30 ; 10$ with heart transplant, 7 kidney, and 13 liver). The remaining 946 records were considered as 'deaths with CKS' and were used for this analysis.

\section{Causes of death among persons with CKS and differences compared with the general population}

To identify the underlying cause of death of the 946 persons with CKS, we reviewed the individual records in the multiple-causes-ofdeath database. KS was recorded as the underlying cause on 486 (51.4\%) death certificates. Of these, 275 (56.6\%) had both KS and one or more lethal pathologies written as the underlying cause (for example, malignant tumours, circulatory system diseases, and respiratory system diseases). In these cases, the lethal pathology was considered as the underlying cause (as mentioned, CKS is rarely considered an actual cause of death); if more than one lethal pathology was written, we selected the most plausible cause based on an internationally accepted hierarchy of causes of death in ICD-9, which is used by ISTAT. In the remaining 211 (43.4\%) of the 486 death certificates with KS as the underlying cause, KS was the only underlying cause; in these cases, we reviewed the 'other causes resulting in the underlying cause' to determine whether they included one or more lethal pathologies; this was the case in 95 of the 211 certificates (again, if more than one pathology was identified, the underlying cause was assigned based on the above-mentioned hierarchy). For the remaining 116 of the 211 certificates, no lethal pathology was found and KS was considered as the cause of death (death 'due to' or 'caused by' CKS). We then assigned the ICD-9 code to the 830 underlying causes of deaths, that is, excluding the 116 cases in which KS was the only identified cause (herein referred to as 'KS alone'), for which no specific ICD-9 code exists.
To determine whether there were excesses or deficits for specific underlying causes of death among these 830 deceased persons with CKS, we compared the observed number of deaths with the expected number of deaths, calculated on the basis of the proportion of deaths due to that underlying cause among the same-age general population of persons who died in the same period (that is, given that the underlying cause is the only cause that is codified, it is the only cause that can be compared with the official statistics for the general population). The ratio of observed-to-expected cases can be considered as standardised mortality ratio (SMR)-like (herein referred to as 'SMR'). The SMR was calculated for major groups of pathologies (for example, cardiovascular disease, respiratory disease) and for some specific pathologies (for example, specific cancers). The 95\% confidence intervals (CIs) were calculated based on the Byar's formula, which provides accurate approximations when working with small numbers (Breslow and Day, 1987).

\section{Geographical distribution of deceased persons with CKS}

For the geographical analysis, we calculated the SMR for the region of death, which was available for all 946 persons (Italy is divided into 20 regions, each of which is divided into provinces). Given that the area of birth is an important determinant because HHV8 is mostly acquired during childhood (Whitby et al, 2000; Cattani et al, 2003), we also calculated the SMRs for the region of birth (not recorded on the multiple-causes-of-death records), by linking the multiple-causes-of-death records with the National Mortality Database, using the individual anonymous six-digit identification code adopted for both databases. However, as the region of birth has been recorded in the National Mortality Database only since 1998, this linkage was only possible for 679 persons. Finally, for the regions of birth for which a significant SMR was found, we also calculated the SMRs by province of birth.

When calculating the SMRs for the region of death and region of birth, the reference population was Italy's entire general population for the same period. When calculating the provincial SMRs, the reference population was that of the single regions in the same period.

\section{RESULTS}

A total of 946 deaths among persons with CKS in the Italian population of persons $\geqslant 65$ years of age (range 65-101 years) were evaluated (619 in men and 327 in women). The distribution of age groups (that is, $65-74,75-84,85-94$, and $\geqslant 95$ years) significantly differed by gender (Mann-Whitney test), with a median age of 82 years for men and 85 years for women. Only $171(18.1 \%)$ persons were $<75$ years of age. When we carried out the analyses separately for men and women, no significant differences were found with respect to the results for the two genders combined.

Of the 946 deaths, $65.9 \%$ were attributable to non-neoplastic conditions, $21.9 \%$ to malignancies, and $12.2 \%$ to KS (that is, deaths for which no lethal pathology was identified). The SMRs and the 95\% CI for the major groups of underlying causes of death are shown in Table 1. Compared with the general population, our study population had a marginal deficit for all cancers combined. There was also a deficit for diseases of the nervous system. When considering all cardiovascular diseases combined, a small deficit was found. This included a significant deficit for cerebrovascular disease (SMR: 0.52; 95\% CI: $0.41-0.66$ ) and ischaemic heart disease (SMR: 0.69; 95\% CI: 0.56-0.85) (data not shown in the table), whereas there was a nearly two-fold excess for heart failure (SMR: 1.88; 95\% CI: $1.26-2.68$ ) and a small excess (though not significant) for hypertension (SMR: 1.22; 95\% CI: 0.89-1.63).

There was an excess for both respiratory and genitourinary diseases. The excess for respiratory diseases was mainly attributable 
to chronic obstructive pulmonary disease (COPD) and allied conditions (SMR: 1.86; 95\% CI: 1.45-2.37) and bronchopneumonia/pneumonia (SMR: 1.90; 95\% CI: $1.28-2.74$ ), whereas that for genitourinary diseases was mainly attributable to chronic renal failure (SMR: 6.47; 95\% CI: 4.70-8.80) (data not shown in the table). There was no association for digestive diseases combined,

Table I Underlying causes of death among persons with classic Kaposi's sarcoma; Italy, 1995-2002

\begin{tabular}{|c|c|c|c|c|c|}
\hline Cause of death & ICD-9 & Observed & Expected & SMR & $95 \mathrm{Cl} \%$ \\
\hline All cancers & $140-239$ & 207 & 241.7 & 0.86 & $0.74-0.98$ \\
\hline Nervous system diseases ${ }^{a}$ & $320-359$ & 8 & 22.0 & 0.36 & $0.16-0.72$ \\
\hline Cardiovascular diseases $^{\mathrm{b}}$ & $390-459$ & 343 & 419.6 & 0.82 & $0.73-0.91$ \\
\hline Respiratory diseases ${ }^{c}$ & $460-519$ & 128 & 67.6 & 1.89 & $1.58-2.25$ \\
\hline Genitourinary diseases $^{\mathrm{d}}$ & $580-630$ & 43 & 14.3 & 3.0 & $2.18-4.05$ \\
\hline Digestive diseases ${ }^{\mathrm{e}}$ & $520-579$ & 29 & 41.1 & 0.71 & $0.47-1.01$ \\
\hline Other causes $^{f}$ & - & 72 & - & - & - \\
\hline Kaposi's sarcoma alone ${ }^{g}$ & - & 116 & - & - & - \\
\hline Total & & 946 & & & \\
\hline
\end{tabular}

ancludes Parkinson's disease (3), encephalopathy (3), multiple sclerosis (1), and myelopathy (not otherwise specified) (I). ' Includes hypertensive disease (46), ischaemic heart disease (93), heart failure (30), cerebrovascular disease (68), other forms of heart disease (70), pulmonary embolism, (3) and other vascular diseases (33). Includes chronic obstructive pulmonary diseases/emphysema/asthma (68), bronchopneumonia (29), pneumothorax (2), pulmonary fibrosis (3), and other (26, of which 6 pulmonary oedema). IIncludes chronic renal failure (4I) and urinary tract infection (2). 'Includes cirrhosis (12), ulcer (4), chronic hepatitis (5), intestinal occlusion (2), pancreatitis/biliary disease (3), ascites/peritonitis (2), and liver failure (1). fIncludes infectious and parasitic diseases (3), diabetes (22), autoimmune diseases (12) (for example, rheumatoid arthritis, polymyositis, systemic lupus erythematosus, and Sjögren syndrome), dementia (9), anaemia (16), bone marrow aplasia (5), and other (5). 'Death certificates without other underlying causes of death except Kaposi's sarcoma. whereas there was a non-significant deficit for cirrhosis (the most common digestive disease in our study) (SMR: 0.75; 95\% CI: 0.39-1.31). Of the other causes, there was a deficit for senile dementia (SMR: 0.39; 95\% CI: $0.18-0.74$ ) and a slight deficit (though not significant) for diabetes (SMR: 0.68; 95\% CI: $0.42-1.02$ ).

For $116(12.2 \%)$ death certificates, there was no mention of any lethal pathology; thus KS was considered as the cause of death ('KS alone'). Of these cases, KS was disseminated or had visceral or nodal involvement $(n=46 ; 39.7 \%)$, or there was mention of neoplastic cachexia $(n=39 ; 33.6 \%)$ or senile decay or marasmus ( $n=10 ; 8.6 \%)$. In the remaining $21(18.1 \%)$ cases, various complications were reported, including multiple skin ulcerations/necrosis $(n=3)$, toxicity to chemotherapy or radiotherapy $(n=2)$, lowerlimb amputations $(n=2)$, and anasarca $(n=2)$, among others.

A primary cancer in addition to KS was recorded on 207 (21.9\%) death certificates ( 144 men and 63 women) (Table 2). There was a deficit for all solid cancers combined. When considering specific sites, a deficit was found for lung, stomach and colon-rectum cancer; an excess, though not significant, was found for brain and prostate cancer.

For all malignant neoplasms of lymphatic and hematopoietic tissue, there was a more than four-fold excess, which was due to chronic lymphocytic leukaemia (CLL), Hodgkin's lymphoma (HL), non-Hodgkin's lymphoma (NHL), and multiple myeloma in both men and women.

Double primary cancers (that is, two cancers in addition to $\mathrm{CKS}$ ) were recorded on 17 certificates $(8.2 \%$; 13 men and 4 women); 9 were solid-tumour pairs, 5 were solid/haematopoietictumour pairs ( 3 with CLL), and 3 were haematopoietic-tumour pairs (NHL/leukaemia; CLL/erythroleukaemia; CLL/Richter's syndrome).

Regarding the distribution by region of death, a wide heterogeneity emerged. There was an approximately three-fold excess for Sardinia, an approximately two-fold excess for Puglia and Calabria (southern Italy), a 1.5-fold excess for Lombardy (northern

Table 2 Additional cancers among persons with classic Kaposi's sarcoma; Italy, 1995-2002

\begin{tabular}{|c|c|c|c|c|c|}
\hline All solid cancers & $140-199,210-239$ & 125 & 223.04 & 0.56 & $0.47-0.67$ \\
\hline Stomach & $|5|$ & 6 & 18.79 & 0.32 & $0.12-0.69$ \\
\hline Liver & 155 & 7 & 8.20 & 0.85 & $0.34-1.76$ \\
\hline Lung & $161-162$ & 19 & 46.50 & 0.41 & $0.25-0.64$ \\
\hline Female breast & 174 & 9 & 14.27 & 0.63 & $0.29-1.19$ \\
\hline Prostate & 185 & 19 & 13.32 & 1.43 & $0.86-2.23$ \\
\hline Secondary neoplasms ${ }^{c}$ & - & 18 & - & - & - \\
\hline Lymphatic and haematopoietic diseases & $200-208$ & 82 & 18.65 & 4.40 & $3.50-5.50$ \\
\hline Non-Hodgkin's lymphoma & 200,202 & 28 & 6.63 & 4.22 & $2.81-6.13$ \\
\hline Hodgkin's lymphoma & 201 & 5 & 0.42 & 11.80 & $4.03-29.2$ \\
\hline Multiple myeloma & 203 & 9 & 3.97 & 2.27 & $1.03-4.27$ \\
\hline Acute leukaemia $^{\mathrm{e}}$ & $204.0,205.0$ & 2 & - & - & - \\
\hline All cancers & $140-239$ & 207 & 241.7 & 0.86 & $0.74-0.98$ \\
\hline
\end{tabular}

ancludes glioma (2), glioblastoma (I), astrocytoma (3), and cerebral neoplasia (not otherwise specified) ( 1 ). ' Includes cancers of the oesophagus (2), pancreas (3), kidney (2), bladder (I), vulva/vagina (2), pleura (2), melanoma skin (I), non-melanoma skin (I), penis (2), gastrointestinal tract not otherwise specified (4), larynx (I), and uterus (4: 2 cervix and 2 endometrium). 'Includes liver, adrenal glands, lung, and brain metastasis of unknown primary sites. Includes cerebral lymphoma (I, age 75), primary effusion lymphoma (I, age 9I), cutaneous lymphoma (I), and lymphoma (not otherwise specified) (2). 'Includes myeloid (I) and leukaemia (not otherwise specified) (I). 'Includes chronic lymphocytic leukaemia (2I) and hairy cell leukaemia (I). IIncludes chronic myelogenous leukaemia (I), polycythemia vera (I), essential thrombocythemia (I), and chronic idiopathic myelofibrosis (I). 'Includes Waldenström's macroglobulinemia (I), Castleman's disease (I), gammopathy (not otherwise specified) (I), and lymphoproliferative diseases (not otherwise specified) (2) 
Table 3 Mortality by region of birth among persons with classic Kaposi's sarcoma; Italy, 1998-2002

\begin{tabular}{|c|c|c|c|c|c|}
\hline Region & $\begin{array}{l}\text { No. of } \\
\text { deaths }\end{array}$ & $\begin{array}{l}\text { Crude } \\
\text { rates }\end{array}$ & Expected & SMR & $95 \% \mathrm{Cl}$ \\
\hline \multicolumn{6}{|l|}{ Northern } \\
\hline Piedmont & 16 & 0.36 & 57.2 & 0.28 & $(0.16-0.45)$ \\
\hline Valle d'Aosta & I & 0.88 & 1.5 & 0.68 & $(0.01-3.7)$ \\
\hline Liguria & 12 & 0.60 & 26.1 & 0.46 & $(0.24-0.80)$ \\
\hline Lombardy & 132 & 1.65 & 103.9 & 1.27 & $(1.06-1.50)$ \\
\hline Trentino-Alto Adige & 3 & 0.38 & 10.2 & 0.29 & $(0.06-0.86)$ \\
\hline Veneto & 23 & 0.57 & 52.5 & 0.44 & $(0.28-0.66)$ \\
\hline Friuli-Venezia Giulia & 3 & 0.24 & 16.3 & 0.18 & $(0.04-1.35)$ \\
\hline Emilia-Romagna & 60 & 1.36 & 57.2 & 1.05 & $(0.80-1.35)$ \\
\hline \multicolumn{6}{|l|}{ Central } \\
\hline Marche & $\mid 1$ & 0.70 & 20.4 & 0.54 & $(0.27-0.96)$ \\
\hline Tuscany & 16 & 0.41 & 50.5 & 0.32 & $(0.18-0.51)$ \\
\hline Umbria & 4 & 0.43 & 12.1 & 0.33 & $(0.09-0.85)$ \\
\hline Latium & 14 & 0.31 & 58.8 & 0.24 & $(0.13-0.40)$ \\
\hline \multicolumn{6}{|l|}{ Southern } \\
\hline Campania & 61 & 1.54 & 51.6 & 1.18 & $(0.90-\mid .52)$ \\
\hline Abruzzi & 13 & 1.02 & 16.5 & 0.79 & $(0.42-1.35)$ \\
\hline Molise & 3 & 0.89 & 4.4 & 0.68 & $(0.14-1.99)$ \\
\hline Puglia & 115 & 3.69 & 40.5 & 2.84 & $(2.34-3.4 I)$ \\
\hline Basilicata & 17 & 3.14 & 7.0 & 2.41 & $(1.4-3.89)$ \\
\hline Calabria & 58 & 3.44 & 21.9 & 2.65 & $(2.01-3.42)$ \\
\hline \multicolumn{6}{|l|}{ Insular } \\
\hline Sicily & 72 & 1.74 & 53.7 & 1.34 & $(1.05-1.69)$ \\
\hline Sardinia & 45 & 3.53 & 16.6 & 2.72 & $(1.98-3.63)$ \\
\hline Italy & 679 & 1.30 & 679.0 & 1.00 & \\
\hline
\end{tabular}

Italy), and a non-significant excess (1.6-fold) for Basilicata (southern Italy).

The distribution of deaths by region of birth (available for 679 persons) (Table 3) was similar to that by region of death, with a more than two-fold excess for Sardinia, Calabria, and Puglia, and a 1.3-fold excess for Lombardy. Basilicata (2.4-fold) and Sicily (1.3-fold) also showed a significant excess, and Campania (southern Italy) had a slight non-significant excess.

The analysis of SMRs by province of birth (data not shown in the table) revealed excesses for two provinces in Lombardy, in particular, Cremona (SMR: 4.33; 95\% CI: 2.80-6.49) and Lodi (SMR: 5.98 ; 95\% CI: 3.53-9.72); the Taranto province in Puglia (SMR: $1.69 ; 95 \%$ CI: $1.12-2.47$ ); and the Matera province in Basilicata (SMR: 2.06; 95\% CI: $1.03-3.71$ ). In Sardinia, two provinces showed non-significant excesses, Sassari (SMR: 1.52; 95\% CI: $0.91-2.37$ ) and Oristano (SMR: 1.20 ; 95\% CI: $0.44-2.61$ ). A deficit was found for two provinces in Lombardy, that is, Varese (SMR: 0.42; 95\% CI: 0.14-0.98) and Milano (SMR: 0.63; 95\% CI: $0.43-0.88$ ), and for the province of Catanzaro in Calabria (SMR: 0.28 ; $95 \%$ CI: $0.01-0.82)$.

\section{DISCUSSION}

The main findings of our study were that the leading underlying causes of death among deceased elderly persons with CKS were non-neoplastic conditions (65.9\%), malignancies (21.9\%), and ' $\mathrm{KS}$ alone' $(12.2 \%)$ (that is, deaths for which CKS was assigned as the underlying cause). For non-neoplastic conditions, we observed an excess for respiratory and genitourinary diseases. Regarding malignancies, though there was an excess for all lymphoid malignancies combined, which is consistent with most previous studies (Iscovich et al, 1999a, b; Cannon et al, 2000), it was balanced by a deficit for all solid cancers, also previously reported (Franceschi et al, 1996; Hjalgrim et al, 1997; Iscovich et al, 1999a, b).

Regarding lymphoid malignancies, the 11-fold excess for CLL confirms the significantly increased risk of KS among persons with CLL (Iscovich et al, 1999b; Hisada et al, 2001). The four-fold excess for NHL is also consistent with previous studies (Iscovich et al, 1999a,b; Cannon et al, 2000). Although no information was available on the site or type of NHL, one death for primary effusion lymphoma is of interest, given the rarity of this HHV8-associated neoplasm among HIV-negative persons (Ascoli et al, 2002). With respect to the nearly 12 -fold excess for HL and the 2.2 -fold excess for myeloma (borderline significance), again, our findings confirm previous reports (Iscovich et al, 1999b; Cannon et al, 2000; Serraino et al, 2007).

Regarding solid cancers, the deficit for lung cancer, also reported in other studies (Dictor and Attewell, 1988; Biggar et al, 1994; Hjalgrim et al, 1997; Iscovich et al, 1999a, b; Goedert et al, 2002), could be explained by the inverse association between cigarette smoking and CKS (Anderson et al, 2008). However, our results are only in part consistent with this association, in which certain causes of smoking-attributable deaths showed a deficit (smoking-associated vascular mortality: ischaemic heart disease and cerebrovascular disease), whereas others showed an excess (smoking-related respiratory mortality: COPD and allied conditions). In any case, the literature on the association between CKS and cardiovascular and respiratory diseases is conflicting (Goedert et al, 2002; Guttman-Yassky et al, 2006; Anderson et al, 2008).

Of interest is the finding that $17(8.2 \%)$ of the 207 persons with malignancies as the cause of death had double primary cancer. Although this number is small, ours is the first study to measure the occurrence of two independent primary cancers in separate organs in persons with CKS (previous studies were case reports) (Cottoni et al, 2002).

Although direct comparisons are difficult, the pattern of excesses/deficits for cancers in our study showed both similarities and differences when compared with persons with HIV/AIDS and transplant recipients (Grulich et al, 2007; Serraino et al, 2007; Dal Maso et al, 2009). In particular, we found a deficit for all cancers combined, compared with an excess reported for the other populations; lymphoid malignancies showed an excess in both our population and the others. Our deficit for lung cancer is in contrast to the excess for the other populations. The similarities for lymphoid malignancies could reflect immunological perturbations (immunodepression in persons with HIV/AIDS and transplant recipients and immunesenescence/inflammaging (Ostan et al, 2008) in elderly persons with CKS), whereas the differences for solid cancers could reflect different lifestyles/risk factors.

With regard to non-neoplastic diseases, the six-fold excess for chronic renal failure is consistent with the more than four-fold excess for kidney failure/dialysis in persons with CKS (Anderson et al, 2008), which, however, remains unexplained. Persons with chronic renal failure are at risk of developing HHV8-related diseases, and $\mathrm{KS}$ is a rare complication of glomerular diseases (Agbaht et al, 2007).

Concerning the considerable proportion of deaths $(12.2 \%)$ that we assumed were actually caused by CKS, on $>90 \%$ of these death certificates there were indications of the most aggressive forms of CKS (Brambilla et al, 2003), in particular, visceral/nodal involvement, complications related to therapy, or neoplastic cachexia (the remaining $10 \%$ were persons with senile decay). For the other persons with CKS yet who died of other causes, there was no indication of the specific stage of CKS, which is not recorded on death certificates. However, we can assume that CKS was not advanced, given that there was no mention of advanced disease anywhere on the death certificate. With regard to the length of survival, though this information is not available on death certificates, if we compare the median age at diagnosis in Italy (Dal Maso et al, 2005) to the median age at death in our study, we 
can roughly calculate that survival is $\sim 10$ years, which is consistent with previous studies (Brambilla et al, 1994; Franceschi et al, 1996).

The geographical analysis showed a wide heterogeneity, though the reasons for the findings are unknown. In particular, our results confirmed that being born in southern Italy or the Islands is a risk factor for CKS (Geddes et al, 1995; Dal Maso et al, 2005), and we identified the specific regions in these areas. The results also revealed an excess for persons born in two adjacent provinces in the northern region of Lombardy, which is consistent with the increased incidence of CKS and high HHV8 seroprevalence in another adjacent province (Ascoli et al, 2001; Tanzi et al, 2005). These provinces are located in the Po Valley, which, together with Sardinia, Sicily, and Puglia, has shown evidence of a higher incidence of CKS and seroprevalence of HHV8, compared with other areas in Italy (Lospalluti et al, 1995; Calabro et al, 1998; Whitby et al, 2000; Cattani et al, 2003). This could be related to environmental risks, including having been born in areas with endemic malaria (Geddes et $a l, 1995)$ and exposure to bloodsucking insects (Coluzzi et al, 2002; Ascoli et al, 2006).

In drawing conclusions, some potential limits need to be mentioned. We excluded the 89 persons $<65$ years of age, some of whom may have been non-AIDS KS. Conversely, we may have included cases of iatrogenic (non-transplant) KS (that is, the 12 deaths for which the underlying cause was an autoimmune disease), though the relationship between CKS and iatrogenic KS is ambiguous and perhaps artificial. Regarding ascertainment bias, we are reasonably sure that there were no false positives, simply because of the peculiarity of the term 'Kaposi' and considering that in Italy KS has been diagnosed and reported as a cause of death for a number of decades using procedures that are homogeneous throughout the country. However, we cannot exclude the possibility of false negatives, a limitation that is inherent to death certificates (Redelings et al, 2007). Moreover, in comparing the two data sources, in the National Mortality Database some pathologies may be underestimated or overestimated, which would have an effect on our results. For certificates with both KS and another pathology as the underlying cause, we defined the lethal pathology as the cause, so that we may have underestimated the number of deaths for CKS alone and/or overestimated the number of deaths for other causes. Furthermore, some of the persons for whom the region of birth was not available may have been born outside Italy and acquired HHV8 infection abroad. However, this is extremely unlikely, given the advanced age of our population and that mass immigration in Italy is a very recent phenomenon. Finally, though not a limit of the study, it should be stressed that we used mortality data and that consequently not all persons with KS were identified. Nonetheless, it was not our objective to use mortality data as an indicator of prevalence.

To the best of our knowledge, this is the first populationbased investigation of cause-specific mortality among deceased persons with CKS, which included a large number of cases (total of 946). Moreover, the results, which cover an extensive period, refer to Italy's entire population (about 57 million); previous population-based studies on CKS in Italy were based on incidence data provided by a network of cancer registries, which does not cover the entire country (Dal Maso et al, 2005). Though referring specifically to Italy, the results are also informative for other countries and populations and all cases of CKS in general.

\section{REFERENCES}

Agbaht K, Pepedil F, Kirkpantur A, Yilmaz R, Arici M, Turgan C (2007) A case of Kaposi's sarcoma following treatment of membranoproliferative glomerulonephritis and a review of the literature. Ren Fail 29: 107-110 Anderson LA, Lauria C, Romano N, Brown EE, Whitby D, Graubard BI, Li Y, Messina A, Gafa L, Vitale F, Goedert JJ (2008) Risk factors for classical Kaposi's sarcoma in a population-based case-control study in Sicily. Cancer Epidemiol Biomarkers Prev 17: 3435-3443

Ascoli V, Belli S, Benedetti M, Trinca S, Ricci P, Comba P (2001) High incidence of classic Kaposi's sarcoma in Mantua, Po Valley, Northern Italy (1989-1998). Br J Cancer 85: 379-382

Ascoli V, Facchinelli L, Valerio L, Zucchetto A, Dal Maso L, Coluzzi M (2006) Distribution of mosquito species in areas with high and low incidence of classic Kaposi's sarcoma and seroprevalence for HHV-8. Med Vet Entomol 20: 198-208

Ascoli V, Lo Coco F, Torelli G, Vallisa D, Cavanna L, Bergonzi C, Luppi M (2002) Human herpesvirus 8-associated primary effusion lymphoma in HIV patients: a clinicopidemiologic variant resembling classic Kaposi's sarcoma. Haematologica 87: 339-343

Biggar RJ, Curtis RE, Cote TR, Rabkin CS, Melbye M (1994) Risk of other cancers following Kaposi's sarcoma: relation to acquired immunodeficiency syndrome. Am J Epidemiol 139: 362-368

Brambilla L, Boneschi V, Taglioni M, Ferrucci S (2003) Staging of classic Kaposi's sarcoma: a useful tool for therapeutic choices. Eur J Dermatol 13: 83-86

Brambilla L, Labianca R, Boneschi V, Fossati S, Dallavalle G, Finzi AF, Luporini G (1994) Mediterranean Kaposi's sarcoma in the elderly. A randomized study of oral etoposide $v s$ vinblastine. Cancer 74: $2873-2878$

Breslow NE, Day NE (1987) Statistical methods in cancer research, volume II - the design and analysis of cohort studies. IARC Scientific publications No. 82

Calabro ML, Sheldon J, Favero A, Simpson GR, Fiore JR, Gomes E, Angarano G, Chieco-Bianchi L, Schulz TF (1998) Seroprevalence of Kaposi's sarcoma-associated herpesvirus/human herpesvirus 8 in several regions of Italy. J Hum Virol 1: 207-213

Cannon MJ, Flanders WD, Pellett PE (2000) Occurrence of primary cancers in association with multiple myeloma and Kaposi's sarcoma in the United States, 1973-1995. Int J Cancer 85: 453-456
Cattani P, Cerimele F, Porta D, Graffeo R, Ranno S, Marchetti S, Ricci R, Capodicasa N, Fuga L, Amico R, Cherchi G, Gazzilli M, Zanetti S, Fadda G (2003) Age-specific seroprevalence of Human Herpesvirus 8 in Mediterranean regions. Clin Microbiol Infect 9: $274-279$

Coluzzi M, Manno D, Guzzinati S, Tognazzo S, Zambon P, Arca B, Costantini C, Ascoli V (2002) The bloodsucking arthropod bite as possible cofactor in the transmission of human herpesvirus- 8 infection and in the expression of Kaposi's sarcoma disease. Parassitologia 44: $123-129$

Cottoni F, Montesu MA, Lissia A, Dore F, Posadino AM, Farris A, Cossu A, Cerimele D (2002) Merkel cell carcinoma, Kaposi's sarcoma, basal cell carcinoma and keratoacanthoma: multiple association in a patient with chronic lymphatic leukaemia. Br J Dermatol 147: $1029-1031$

Dal Maso L, Polesel J, Ascoli V, Zambon P, Budroni M, Ferretti S, Tumino R, Tagliabue G, Patriarca S, Federico M, Vercelli M, Giacomin A, Vicario G, Bellu F, Falcini F, Crocetti E, De Lisi V, Vitarelli S, Piffer S, Stracci F, Serraino D, Rezza G, Franceschi S (2005) Classic Kaposi's sarcoma in Italy, 1985-1998. Br J Cancer 92: 188-193

Dal Maso L, Polesel J, Serraino D, Lise M, Piselli P, Falcini F, Russo A, Intrieri T, Vercelli M, Zambon P, Tagliabue G, Zanetti R, Federico M, Limina RM, Mangone L, De Lisi V, Stracci F, Ferretti S, Piffer S, Budroni M, Donato A, Giacomin A, Bellu F, Fusco M, Madeddu A, Vitarelli S, Tessandori R, Tumino R, Suligoi B, Franceschi S (2009) Pattern of cancer risk in persons with AIDS in Italy in the HAART era. Br J Cancer 100: $840-847$

Dictor M, Attewell R (1988) Epidemiology of Kaposi's sarcoma in Sweden prior to the acquired immunodeficiency syndrome. Int $J$ Cancer 42: $346-351$

Franceschi S, Arniani S, Balzi D, Geddes M (1996) Survival of classic Kaposi's sarcoma and risk of second cancer. $\mathrm{Br} J$ Cancer 74: $1812-1814$

Geddes M, Franceschi S, Balzi D, Arniani S, Gafa L, Zanetti R (1995) Birthplace and classic Kaposi's sarcoma in Italy. Associazione Italiana Registri Tumori. J Natl Cancer Inst 87: 1015-1017 
Goedert JJ, Vitale F, Lauria C, Serraino D, Tamburini M, Montella M, Messina A, Brown EE, Rezza G, Gafa L, Romano N (2002) Risk factors for classical Kaposi's sarcoma. J Natl Cancer Inst 94: 1712-1718

Grulich AE, van Leeuwen MT, Falster MO, Vajdic CM (2007) Incidence of cancers in people with HIV/AIDS compared with immunosuppressed transplant recipients: a meta-analysis. Lancet 370: 59-67

Guttman-Yassky E, Dubnov J, Kra-Oz Z, Friedman-Birnbaum R, Silbermann M, Barchana M, Bergman R, Sarid R (2006) Classic Kaposi's sarcoma. Which KSHV-seropositive individuals are at risk? Cancer 106: $413-419$

Hiatt KM, Nelson AM, Lichy JH, Fanburg-Smith JC (2008) Classic Kaposi's sarcoma in the United States over the last two decades: a clinicopathologic and molecular study of 438 non-HIV-related Kaposi's sarcoma patients with comparison to HIV-related Kaposi's sarcoma. Mod Pathol 21: $572-582$

Hisada M, Biggar RJ, Greene MH, Fraumeni Jr JF, Travis LB (2001) Solid tumors after chronic lymphocytic leukemia. Blood 98: 1979-1981

Hjalgrim H, Frisch M, Pukkala E, Tulinius H, Ekbom A, Dictor M, Langmark F, Hardarson S, Melbye M (1997) Risk of second cancers in classical Kaposi's sarcoma. Int J Cancer 73: 840-843

Iscovich J, Boffetta P, Brennan P (1999a) Classic Kaposi's sarcoma as a first primary neoplasm. Int J Cancer 80: $173-177$

Iscovich J, Boffetta P, Winkelmann R, Brennan P (1999b) Classic Kaposi's sarcoma as a second primary neoplasm. Int J Cancer 80: 178-182

Israel RA, Rosenberg HM, Curtin LR (1986) Analytical potential for multiple cause-of-death data. Am J Epidemiol 124: 161-179
Lospalluti M, Mastrolonardo M, Loconsole F, Conte A, Rantuccio F (1995) Classical Kaposi's sarcoma: a survey of 163 cases observed in Bari, south Italy. Dermatology 191: $104-108$

Ostan R, Bucci L, Capri M, Salvioli S, Scurti M, Pini E, Monti D, Franceschi C (2008) Immunosenescence and immunogenetics of human longevity. Neuroimmunomodulation 15: 224-240

Redelings MD, Wise M, Sorvillo F (2007) Using multiple cause-of-death data to investigate associations and causality between conditions listed on the death certificate. Am J Epidemiol 166: 104-108

Serraino D, Piselli P, Busnach G, Burra P, Citterio F, Arbustini E, Baccarani U, De Juli E, Pozzetto U, Bellelli S, Polesel J, Pradier C, Dal Maso L, Angeletti C, Carrieri MP, Rezza G, Franceschi S (2007) Risk of cancer following immunosuppression in organ transplant recipients and in HIV-positive individuals in southern Europe. Eur J Cancer 43: 2117-2123

Tanzi E, Zappa A, Caramaschi F, Amendola A, Lasagna D, Gatti L, Ascoli V, Rezza G, Zanetti AR (2005) Human herpesvirus type 8 infection in an area of Northern Italy with high incidence of classical Kaposi's sarcoma. J Med Virol 76: $571-575$

Wall MM, Huang J, Oswald J, McCullen D (2005) Factors associated with reporting multiple causes of death. BMC Med Res Methodol 5: 4

Whitby D, Luppi M, Sabin C, Barozzi P, Di Biase AR, Balli F, Cucci F, Weiss RA, Boshoff C, Torelli G (2000) Detection of antibodies to human herpesvirus 8 in Italian children: evidence for horizontal transmission. Br J Cancer 82: $702-704$

WHO (1994). WHO case definitions for AIDS surveillance in adults and adolescents. In Weekly Epidemiological Record, Vol. 69. pp 273-275 